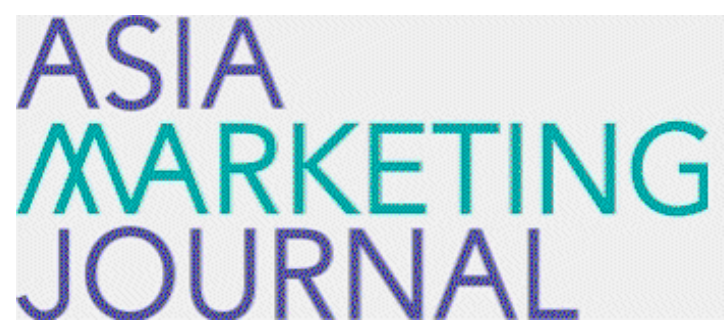

ASIA MARKETING JOURNAL

Volume 19 | Issue 1

Article 4

4-30-2017

\title{
To Conform or Not to Conform : Mixed Conformity Model
}

Yongjee Han

Follow this and additional works at: https://amj.kma.re.kr/journal

Part of the Marketing Commons

\section{Recommended Citation}

Han, Yongjee (2017) "To Conform or Not to Conform : Mixed Conformity Model," Asia Marketing Journal: Vol. 19 : Iss. 1 , Article 4.

Available at: https://doi.org/10.15830/amj.2017.19.1.55

This Article is brought to you for free and open access by Asia Marketing Journal. It has been accepted for inclusion in Asia Marketing Journal by an authorized editor of Asia Marketing Journal. 


\section{To Conform or Not to Conform: Mixed Conformity Model}

Yongjee Han*

This study explores the influence of reference groups depending on the type (in-group versus out-group) and the size (an individual member versus a group as a whole) of reference groups. We propose a mixed conformity model, which suggests that people want to fit in with their in-group but at the same time they want to stand out within their in-group members. We found that in moderately identity-relevant product categories, people tend to diverge from individual members of their in-group while conforming to their in-group as a whole. However, in highly identity-relevant product categories, people conform to their in-group independent of the referent's size. Directions for future research are outlined in order to further establish and understand the proposed phenomenon.

Key words: Reference group, in-group, out-group, identity-relevancy, optimal distinctiveness theory

We do not live in a world of isolation; we interact with one another when forming our opinions, beliefs, and preferences. One of the most pervasive determinants of our behavior is the influence of people around us. We often go shopping with our family or friends; we see what they choose and ask them about their preference or ask for their recommendations. Even when we go shopping alone, other shoppers are around us. We see what other people buy, and it often influences our own choices.

The fact that people act in accordance with a frame of reference produced by the groups to which they belong is a long-accepted and sound premise (Merton and Rossi 1949). Past research has consistently demonstrated that reference groups can influence people's intentions, attitudes, and behaviors (e.g. Hogg and Turner 1987). For example, other members of one's own group influence exercise intentions (Terry and Hogg 1996), evaluations of products and advertisements (Whittler and Spira 2002), product and brand choice (Bearden and Etzel 1982, Park and Lessig 2002). Childres and Rao

\footnotetext{
* Assistant Professor of Marketing School of Business Sungkyunkwan University (yjhan@skku.edu)
} 
(1992) also have documented a congruency between group membership and brand usage. In sum, conformity towards in-group members has been well documented.

However, even casual observation reveals a perplexing contradiction. Consider the following experience of the author: A few months ago, she went shopping with her friend. She was looking for a handbag at a store. She liked two handbags, but she couldn't decide which one to buy. While she was still deciding, her friend who was looking around the store came over to her and said that her friend decided to buy a bag and was pointing at one of the two bags that she was considering buying. Knowing that her friend had chosen the bag, she decided not to buy the same bag and bought the other one. Why would she not want to buy the same bag? This behavior can be explained by research on need for uniqueness.

Past research has demonstrated that consumers have a drive to differentiate themselves from others (Snyder and Fromkin 1980; Ariely and Levav 2000). Snyder and Fromkin suggest that people will make choices that are unique in order to present themselves in a positive light. In Ariely and Levav (2000)'s study, consumers ordering from a menu in a group context chose something other than their favorite item if another group member already selected that item.

One of the attempts to integrate the desire for association and desire for distinctiveness is the theory of optimal distinctiveness (Brewer 1991). The theory postulates a dynamic tension between competing drives for inclusiveness and distinctiveness; people want to be distinctive from out-groups, but the distinctiveness needs to be equalized by association with in-groups. It is assumed that people would not want to diverge from their in-groups. However, as in the author's experience, people want to differentiate themselves from their in-group members to a certain degree. To resolve this issue, the current study proposes a new approach to understanding consumers' group behavior; we suggest a mixed conformity model, which postulates that while people want to fit in with their reference group, they want to stand out within the group. Taking the notion of competing drives of distinctiveness and inclusiveness, we argue that people have the same competing drives when they compare themselves with their in-group members and show that the desire for distinctiveness becomes stronger when the referent is an individual member than when the referent is a group as a whole. Further, past research has shown that people have more desire for uniqueness for product categories in which people signal their identity (Berger and Heath 2007). Therefore, we explore how reference groups' influence varies depending on product categories with different degrees of identity signaling.

This study contributes to our understanding of the influence of reference groups by suggesting 
a new model. It examines the existence of two competing drives that have not been studied and shows when people would diverge from their in-groups. This work not only provides evidence to the proposed model but also enriches our understanding of the effects of two competing derives on reference group influence.

\section{Theoretical Background}

\subsection{The Influence of Reference Groups}

Consumers may purchase products as a result of overt conformity pressures from peer groups, in response to concerns of what others may think of them, or they may react to their product choice and usage (Calder and Burnkrant 1977, Bearden and Rose 1990), or because others have provided information regarding a product's value (Cohen and Golden 1972). Venkatesan (1966) found that naïve subjects were influenced in their evaluation of products by the prior evaluation of confederates of the experimenter who were unanimously and confidently in agreement on their evaluation. He concluded that "group pressure was effective and that individuals tended to conform to the group norm” (Venkatesan 1966, p.386).

Previous research recognizes three motivational influences of reference groups (Park and Lessig 1977). First, the influence of reference groups can be driven by an informational motivation. This influence is similar to the informational or comparative influence suggested by Deutsch and Gerard (1955). An influence is accepted if it is perceived as enhancing the individual's knowledge of his environment and/or his ability to cope with some aspect of this environment. Second, the influence of reference groups can be driven by a utilitarian motivation. Individuals in a product purchasing situation would be expected to comply with the preferences or expectations of another individual or group if they perceive the preferences of another individual or group mediate significant rewards or punishments, and if they believe that their behavior will be visible or known to these others. Third, the influence of reference groups can be driven by value-expressive motivation. In this case, individuals would be expected to associate themselves with their reference group (Kelman 1961). The value-expressive reference group influence is characterized by two different processes. First, individuals utilize reference groups to express themselves or bolster their ego. In this case, there should be a consistency between the desire to express one's self and the psychological image attached to the reference group. Second, individuals are influenced by a value-expressive reference group because of their simple consistency between their self-image and the psychological image attached to the reference group. Thus, an individual responds to the reference group by accepting the

To Conform or Not to Conform: Mixed Conformity Model 57 
recommendations.

The current study does not consider the situations in which consumers can expect rewards or punishments. In this study, reference groups have impacts on consumers' purchase behavior by deriving utilitarian motivation or valueexpressive motivation depending on product categories. When the product category is value-expressive and relevant to identity-signaling, value-expressive motivation would come into play, but when the product category has nothing to do with value-expression or identity-signaling, reference groups will influence consumers through utilitarian motivation.

As elaborated in Grubb and Grathwohl's (1967) work on how consumer goods serve individuals in forming and maintaining desired self-concepts, consumers' need for uniqueness should reflect both self-image and social image enhancement processes. A unique product may be sought out to restore a person's self-view as one who is different from others. Therefore, the effect on the individual is ultimately dependent on the consumer good signaling self-identity or self-image.

Berger and Heath (2007) showed that across individuals and independent of situational pressures, people tend to diverge more in certain product domains than others. People use symbolic domains to make identity inferences about others, but the particular identities that are inferred depend on who else holds the taste. Consequently, who else shares one's taste will have a greater influence on divergence in domains that others use to infer identity. They find that both the taste domain and the group membership of the other people who are engaging in the behavior play a role (Berger and Heath 2007). In non-identity-relevant domains, people should conform to the references of others, regardless of their social group. However, in identity-relevant domains, group membership should have large influences.

The current research examines the influence of reference groups depending on the referent's characteristics. However, this effect will be pronounced when identity-signaling concerns are relevant. Previous research suggests that reference groups have greater influence when the product is identity-signaling (Berger and Heath 2007). Bourne's original theorization regarding reference group influence suggested that reference groups exert greater influence when consumption is more conspicuous (Bourne 1957), presumably because this is when people are most concerned with identity-signaling.

\subsection{Counterconformity}

This study proposes that people may not conform to in-group members when the referent is an individual. Previous research recognizes several motivational processes that underlie social nonconformity. The choice of differentiating material objects can be driven by independence motivation or counterconformity motivation. 
When a person adheres to internal taste and the choice differentiates the decision maker from others, this outcome is just incidental to behavior consistent with personal standards (Nail 1986). In contrast, the differentiating behavior can be driven by the need to feel different from other people. In this case, differentiation is the primary, intended outcome of the person's actions. This need is labeled “counterconformity motivation” (Nail 1986), and it arises when individuals feel a threat to their identity, which occurs when they perceive that they are highly similar to others (Snyder and Fromkin 1977). In both cases, individuals are influenced by other people. However, unlike an individual driven by independence motivation, the couterconforming individual behaves so as to be distinctive from others. My study also focuses on a second motivation that underlies differentiating behavior.

\subsection{Optimal Distinctiveness Theory}

Optimal distinctiveness theory (Brewer 1991) suggests the existence of a dynamic tension between competing drives for distinctiveness and inclusiveness. The origins of optimal distinctiveness theory are linked to evolutionary theory (Brewer 1999). Brewer argued that humans developed in ways that they cannot live independently of other people. Humans need to be part of larger groups in order to survive. Since social groups are fundamental for human prosperity, distinctiveness itself is the motive which determines the "selection and strength of social identity" between social groups (Brewer 2003). Optimal distinctiveness theory states that in-group distinctiveness must be equalized by assimilation, which is an independent yet opposing motive for group identification (Brewer 2003). In other words, this theory suggests a continuum characterized by uniqueness at one extreme and homogeneity at the other. Therefore, an "optimal identity" is one that satisfied the need for inclusion within the in-group as well as the need for distinctiveness between the in-group and outgroup. This theory explains conformity to ingroups and distinctiveness from out-groups. However, it does not shed light on differentiating behavior from in-groups.

\subsection{Mixed Conformity Model}

The current study takes the continuum concept of distinctiveness to explain the existence of differentiating behavior among in-group members. When they compare themselves with their ingroup, people tend to conform to in-group's norm and preference. However, our study proposes that comparison with an individual member of their in-group leads people to differentiate themselves from the referent. When people compare themselves with an individual of their in-group, their position relative to the individual is more salient than 
〈Figure 1〉 Optimal Distinctiveness Model

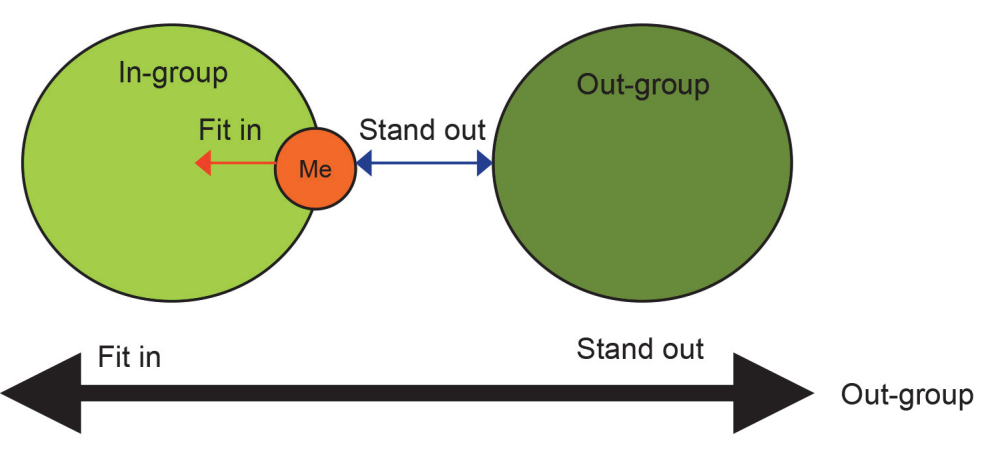

their membership in the in-group. People want to be distinctive from out-groups and want to be associated with their in-groups. However, when social comparison is with an individual of their in-group, need for uniqueness has a bigger influence than desire for association with the in-group. Therefore, an individual referent will increase the influence of need for uniqueness; people are less likely to conform to the individual referent's preference. Further, since the individual referent is a member of the group that the actor belongs to, the actor and the individual referent already share some characteristics. Therefore, it is less likely that the actor would think that his/her distinctiveness from the individual member would hurt his/ her membership in the in-group. Therefore, this article suggests a mixed conformity model, which proposes that people want to fit in with their in-groups as a whole, but they also want to stand out from an individual in-group member. The proposed mixed conformity predicts that people should be more likely to conform to their in-group when the reference is a group as a whole than when the referent is an individual member of the group. We also propose that counter-conformity toward an individual member of an in-group exists only in product categories that are relevant to identity-signaling. When product categories are irrelevant to

〈Figure 2〉 Mixed Conformity Model

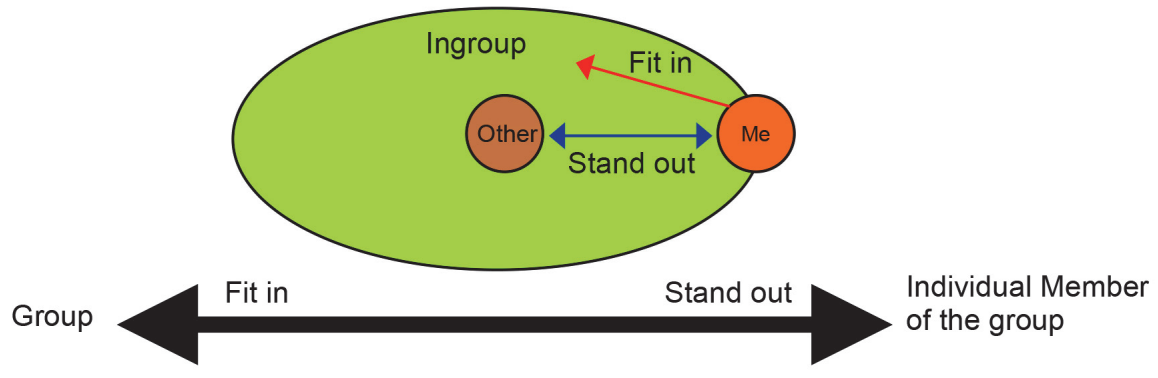


identity-signaling, reference groups will influence consumers through utilitarian motivation. A consumer will comply with other people's preferences independent of reference types when it is the only information that they can use to make a decision.

\section{Method}

32 undergraduate students at a university in the United States participated in the study. The design used is a 2 (reference type: ingroup versus out-group) x 2 (reference size: a group versus an individual member). Four product categories from Berger and Heath (2007) were chosen. They examined where consumers diverge from others and found that across individuals and independent of temporary situational pressures, people tend to diverge more in certain product domains than others. In their study, participants were told that $65 \%$ of others owned option A, 25\% owned option B, and $10 \%$ owned option C. Option C is the choice that establishes the greatest divergence from others. Preference for option C differed substantially across domains. According to their account, these results illustrate that consumers are more likely to diverge from majorities in product domains that are seen as symbolic of identity. From the list of product categories used in their study, we chose four categories that represent different degrees of identitysignaling: Music CDs (most identity-signaling), Sitcom (highly identity-signaling), Backpack (slightly identity-signaling), and Toothpaste (not at all identity-signaling).

\subsection{Procedure}

Subjects were shown two options in each of 4 categories: Sitcom, Music CD, Backpack, and Toothpaste. They chose one of two options in each category. Before they made the decisions, they were informed as to which option a referent individual or a majority of a reference group had chosen. When they were in individualreferent conditions, they were told about the choice of a student who had participated in the experiment before them. When they were in group-referent conditions, they were informed about the choice of a majority of students who had participated in the experiment before them. When participants were in the in-group condition, their reference was a group or an individual from the same school; when they were in the out-group condition, their reference was a group or an individual from West Virginia University. After completing choice tasks for four categories, participants answered questions to measure need for uniqueness (Snyder and Fromkin 1980) and also answered questions for manipulation check. Participants were asked to indicate their agreement with the following statements: 'I feel like a member 
of (the reference group), 'I feel close to (the reference group)', and 'I often think of myself as a member of (the reference group)' on a 7 point scale.

\subsection{Results}

Participants in in-group condition exhibited significantly stronger perceived relationship with the reference group or individual compared to participants in out-group condition $\left(\mathrm{M}_{\text {in-group }}=\right.$ $5.67, \mathrm{M}_{\text {out-group }}=1.80, t(30)=-1.163, p<$ $.05)$, indicating successful manipulation. The main results were analyzed using an ANOVA with reference type (in-group vs. out-group) and reference size (individual vs. group) as between-subjects factors. The dependent variable was conformity to their reference's preference: whether they choose the same option that their reference chose. The proposed hypothesis predicted a two-way interaction of reference type and size such that the influence of reference differs depending on whether the reference is an in-group or an out-group and whether the reference is an individual or a group. The two-way interaction varies across product categories depending on identity relevance. The results show a significant two way interaction between reference type and reference size in Sitcom category $(F(1,28)=4.990, p<.05)$ with no significant main effect. When the referent is an individual, out-group reference induces more conformity than in-group reference $\left(\mathrm{M}_{\text {in-group }}=37.5 \%, \mathrm{M}_{\text {out-group }}=87.5 \%\right)$. On the other hand, when referent is a group, in-group reference induces more conformity

〈Table 1〉 The Effect of Reference Type (Ingroup vs. Outgroup) and Size (Group vs. Individual) on Conformity

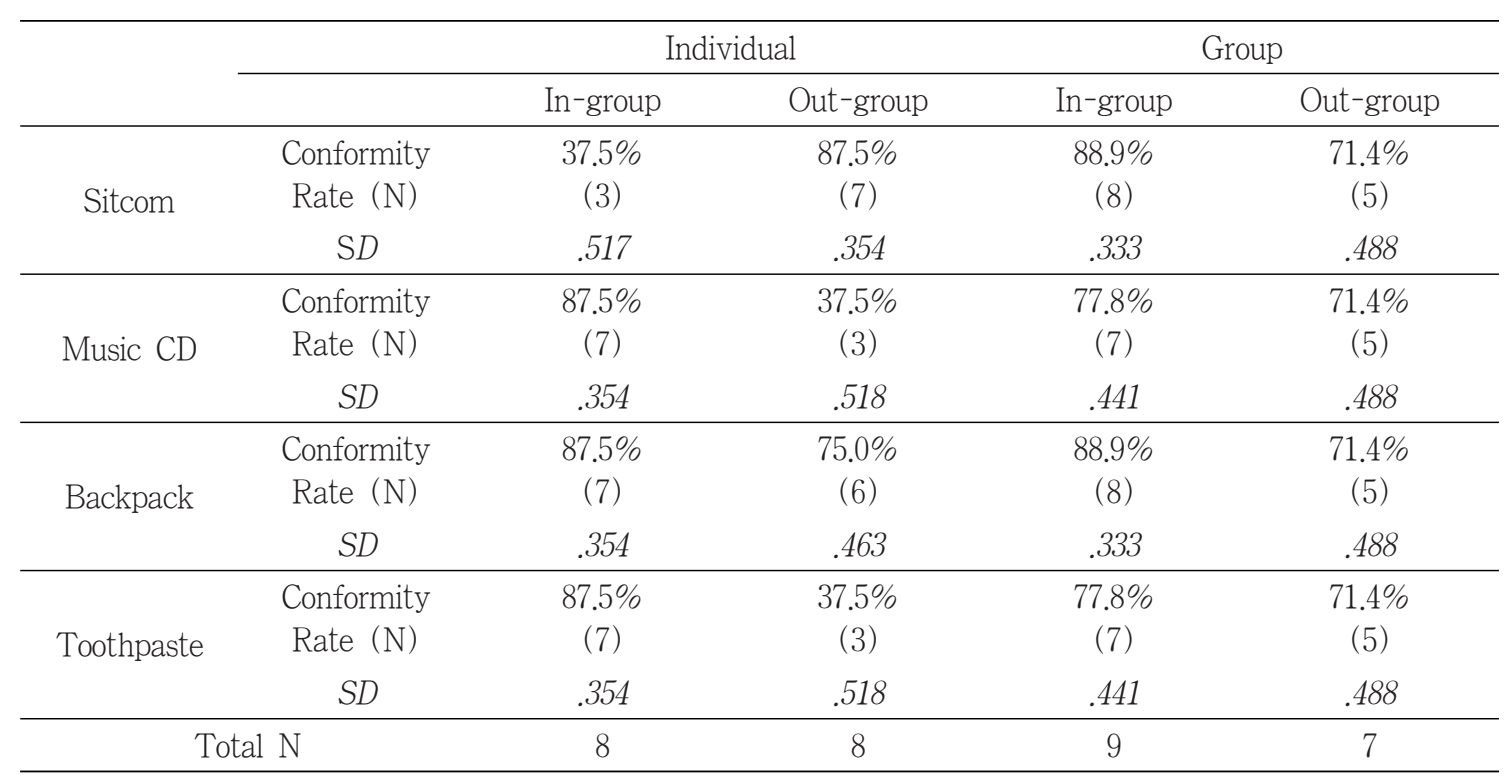


〈Figure 3〉 The Effect of Reference Type (Ingroup vs. Outgroup) and Size (Group vs. Individual) on Conformity

Sitcom

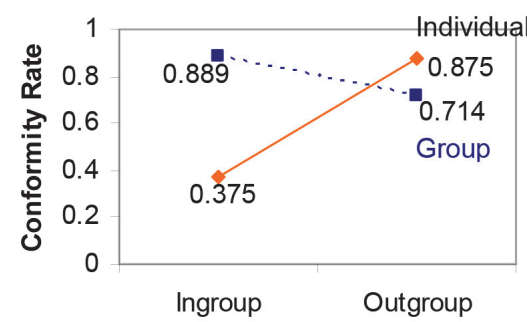

Backpack

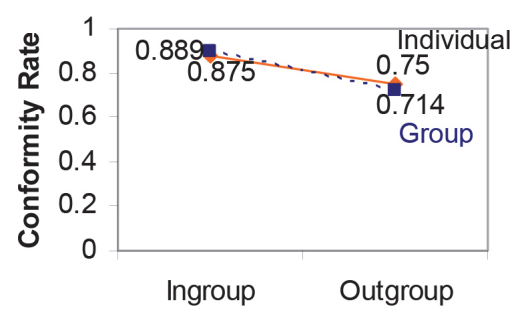

$\left(\mathrm{M}_{\text {in-group }}=88.9 \%, \mathrm{M}_{\text {out-group }}=71.4 \%\right)$. However, in Music CD category, the other identity-signaling category used in the study, the interaction between reference type and reference size is not significant. The analysis reveals only a marginally significant main effect of reference type $(F(1,28)=3.077, p<$ $.01)$. More participants conformed to in-group reference than out-group reference regardless of reference sizes $\left(\mathrm{M}_{\text {in-group }}=82.4 \%, \mathrm{M}_{\text {out-group }}\right.$ $=53.3 \%)$. In the categories that are not relevant to identity-signaling, no main or interaction effects were significant. As expected, participants conformed to what other people had chosen when product categories are irrelevant
Music CD

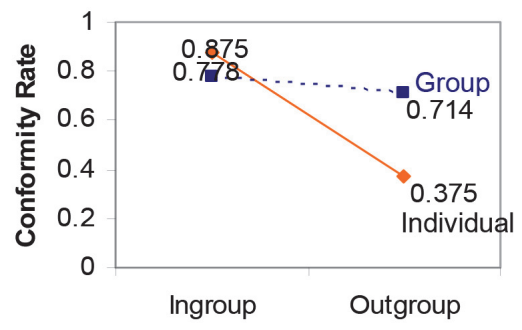

Toothpaste

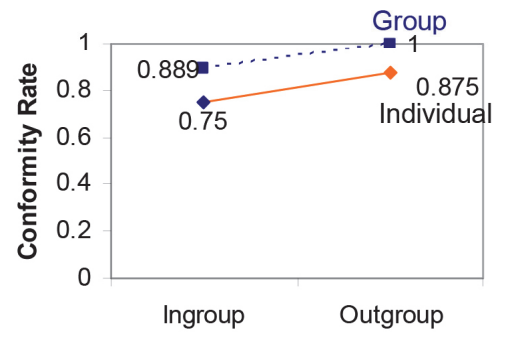

to their identity.

Since the number of participants was relatively small, additional contrast analyses were conducted to check the validity of the conclusion. In order to verify the conclusion that the interaction between reference type and size is significant in Sitcom category but not in Music CD category, the means of individual condition and group condition are compared. The results show that the conformity rate of individual condition $\left(\mathrm{M}_{\text {individual }}=37.5\right)$ and that of group condition $\left(\mathrm{M}_{\text {group }}=88.9\right)$ in Sitcom category are statistically different $(t(15)=-2.464, p<.05)$. However, the conformity rates of individual condition and group condition are not significantly 
different in Music CD condition $(t(13)=1.300$, $p>$.2). Next, we compared the conformity rates in individual conditions. Within individual conditions, the conformity rates of in-group and out-group were significantly different in both Sitcom category and Music CD category (Sitcom: $\mathrm{M}_{\text {in-group }}=37.5 \%, \mathrm{M}_{\text {out-group }}=87.5 \%$, $t(14)=-2.256, p<.05$; Music $\mathrm{CD}: \mathrm{M}_{\text {in-group }}=$ $87.5 \%, \mathrm{M}_{\text {out-group }}=37.5 \% \%, t(14)=-2.256$, $p<.05)$. That is, the data in Sitcom category reveals an interaction between reference type and size while the data in Music CD shows a main effect of reference type. In addition, there was no individual difference in need for uniqueness across different conditions. Therefore, the differences found are due to the manipulated characteristics of reference.

\section{Discussion}

The results provide support for the proposed mixed conformity model; people want to fit in with their in-group, but at the same time they want to be distinctive within their in-group. When people compare their decision with their reference group's decision, they tend to conform to their reference group. However, when they compare their decision with the decision of an individual member of their reference group, a desire for distinctiveness have a bigger impact than a desire for association with the group so that they diverge from the individual member of the reference group. However, the data of this study did not support this pattern in Music CD category.

〈Figure 4〉 The Influence of Reference Depending on Product Categories

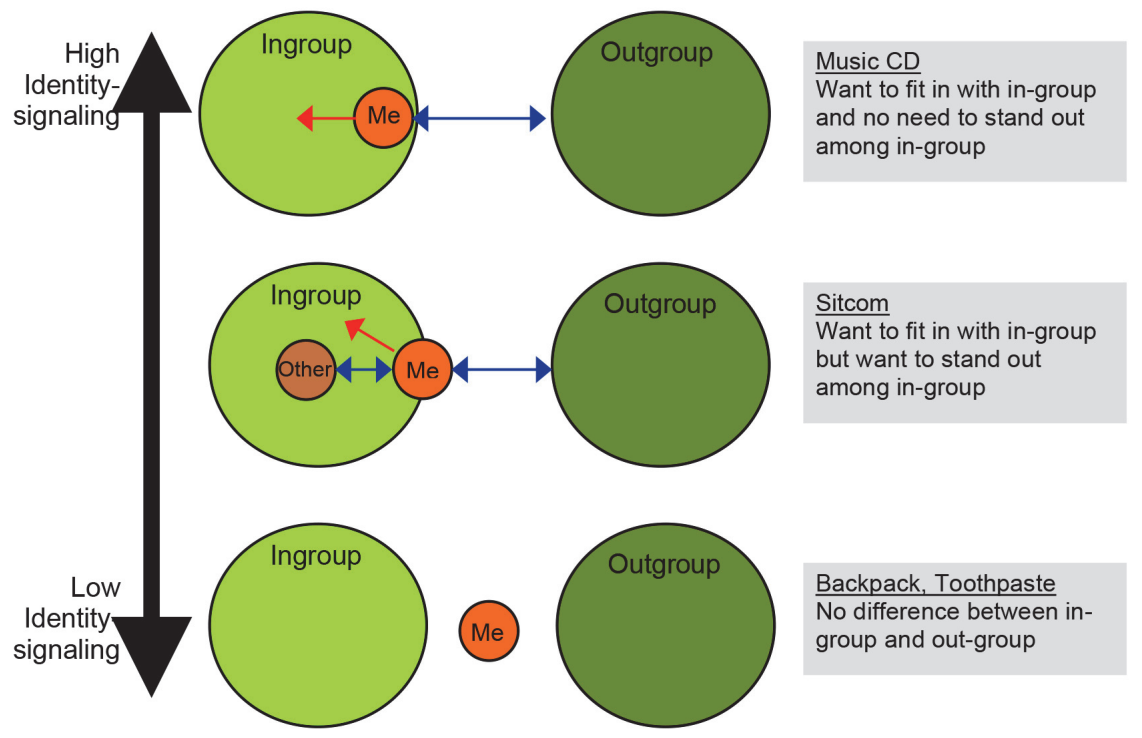

64 ASIA MARKETING JOURNAL Vol. 19 No. 01 April 2017 
According to Berger and Heath (2007), Music CD is more identity-signaling than Sitcom. Therefore, the results of the current study suggest that when the product is highly relevant to an individual's identity, people rather tend to conform to their reference group's preference and have less need for uniqueness than in moderately identity-signaling product category. In sum, mixed conformity appears when the product is moderately identity-signaling.

In this article, we proposed a mixed conformity model that helps to explain when people conform to and diverge from their reference groups. The experimental study supported the model, illustrating that consumers are more likely to diverge from their reference group when the referent is an individual member of the group for moderately identity-signaling products.

Our findings provide managerial implications for marketers. Social influence is often used to affect consumer choice. If a product is highly related to self-identity, marketers can increase consumers' preference by promoting the product as their reference group's preference. The product can be endorsed by either the group as a whole or an individual member of the group. On the other hand, if a product is moderately related to self-identity, marketers should promote the product as their reference group's choice. Promoting the product with an individual member of the group can steer potential consumers away from their product.
A promising direction for future research could be to examine the impact of reference group in a broader range. The out-group that was used in this study was neutral rather than dissociative or negative. White and Dahl (2007) showed that products associated with dissociative reference groups had a greater impact on consumers' negative self-brand connections, product evaluations, and choices than do products associated with out-groups more generally. Therefore, people might show a different behavior pattern with dissociative reference group.

Although we obtained noteworthy findings, some limitations to our studies should be noted. The sample size was small, limiting the power and generalizability of the results. Future research Thus, future research with a bigger sample, and tested in other cultures, is needed to enhance the generalizability of our findings. Moreover, further research with a wider range of product categories will help us better understand when consumers show mixed conformity.

Finally, perceived strength of membership may affect the influence of the reference group. The differentiating behavior induced by an individual referent may not appear if people do not feel confident about their membership with their in-group. Future research might examine the impact of strength of association with in-groups on mixed conformity.

〈Received December 1. 2016〉

〈Revised May 16. 2017〉

〈Accepted May 16. 2017〉 


\section{References}

Ariely, Dan and Jonathan Levav (2000), "Sequential choice in group settings: Taking the road less traveled and less enjoyed," Journal of Consumer Research, 27 (3), 279-290.

Bearden, William O. and Michael J. Etzel (1982), "Reference Group Influence on Product and Brand Purchase Decisions," Journal of Consumer Research, 9 (September), 183-94.

Bearden, William O. and Randall L. Rose (1990), “Attention to Social Comparison Information: An Individual Difference Factor Affecting Consumer Conformity," Journal of Consumer Research, 16 (January), 461-471.

Berger, Jonah and Chip Heath (2007), "Where

Consumers Diverge from Others: IdentitySignaling and Product Domains," Journal of Consumer Research, 34(2), 121-134.

Bourne, Francis S. (1957), "Group Influence in Marketing and Public Relations," in Some Applications of Behavioral Research, ed. Rensis Likert and Samuel P. Hayes, Jr., Basil: UNESCO, 207-57.

Brewer, Marilynn B. (1991), "The Social Self:

On Being the Same and Different at the Same Time," Personality and Social Psychology Bulletin, 17 (October), 475-482.

Brewer, Marilynn B. (2003). Optimal Distinctiveness,
Social Identity, and the Self. In M. Leary and J. Tangney (Eds.), Handbook of Self and Identity. 480-491.

Calder, Bobby J. and Robert E. Burkrant (1977), "Interpersonal Influence on Consumer Behavior: An Attribution Theory Approach," Journal of Consumer Research, 4 (June), 29-38.

Childers, Terry L., and Akshay R. Rao (1992) "The influence of familial and peer-based reference groups on consumer decisions," Journal of Consumer research 19.2 (1992): 198-211.

Cohen, Joel B. and Golden, Ellen, 1972. Informational Social Influence and Product Evaluation. Journal of Allied Psychology 56, $54-59$.

Deutsch, Morton and Gerard, Harold, 1955. A Study of Normative and Informational Social Influences Upon Individual Judgment. Journal of Abnormal and Social Psychology 57, pp. $629-636$.

Grubb, Edward L. and Harrison L. Grathwohl (1967), "Consumer Self-Concept, Symbolism, and Market Behavior: A Theoretical Approach," Journal of Marketing, 31 (October), 22-27.

Hogg, Michael A. and John C. Turner (1987), "Intergroup Behaviour, Self-Stereotyping and the Salience of Social Categories," British Journal of Social Psychology, 26 (4), 325 - 40.

Kelman, Herbert C. (1961), "Processes of Opinion 
Change," Public Opinion Quarterly, 25 (winter), 57-78.

Merton, Robert K. and Alice Kitt Rossi (1949), "Contributions to the Theory of Reference Group Behavior," in Social Theory and Social Structure, ed. Robert K. Merton, New York: The Free Press, 225-275.

Nail, Paul R. (1986), “Toward an Integration of Some Models and Theories of Social Response," Psychological Bulletin, 100 (September), 190-206.

Park, C. Whan and C. Parker Lessig (1981), "Familiarity and Its Impact on Consumer Decision Biases and Heuristics," Journal of Consumer Research, 8 (September), 22330.

Snyder, C. R. and Howard L. Fromkin (1977), "Abnormality as a Positive Characteristic: The Development and Validation of Scale Measuring Need for Uniqueness," Journal of Abnormal Psychology, 86 (October), 518-527. and Howard L. Fromkin (1980), Uniqueness, New York: Plenum.

Terry, Deborah J. and Michael A. Hogg and (1996), "Group norms and the attitudebehavior relationship: A role for group identification," Personality and Social Psychology Bulletin, 22: 776-793.

Venkatesan, M. (1966), "Experimental Study of Consumer Behavior Conformity and Independence," Journal of Marketing Research, 3 (November), 384-7.

White, Katherine and Darren W. Dahl (2007), "Are All Out-Groups Created Equal? Consumer Identity and Dissociative Influence," Journal of Consumer Research, 34 (4), 525-536.

Whittler, Tommy E., and Joan Scattone Spira (2002), "Model's race: A peripheral cue in advertising messages?," Journal of consumer psychology, 12(4), 291-301. 